\title{
Structural Design and Hydrodynamics Analysis of Wave Energy Converter for Falculty of Engineering, Rmu
}

\author{
Isaac Owusu-Nyarko*, Emmanuel Nartey \\ Department of Electrical/Electronics, Regional Maritime University, Accra, Ghana \\ Email address: \\ isaac.owusu-nyarko@rmu.edu.gh (I. Owusu-Nyarko), nattyembongo@hotmail.com (E. Nartey) \\ ${ }^{*}$ Corresponding author
}

\section{To cite this article:}

Isaac Owusu-Nyarko, Emmanuel Nartey. Structural Design and Hydrodynamics Analysis of Wave Energy Converter for Falculty of Engineering, Rmu. Journal of Electrical and Electronic Engineering. Vol. 5, No. 4, 2017, pp. 130-140. doi: 10.11648/j.jeee.20170504.14

Received: March 27, 2017; Accepted: June 20, 2017; Published: July 24, 2017

\begin{abstract}
Due to the continuous fluctuation of the prices of oil and the environmental impact on the economy, a renewable energy becomes debatable issue. The generation of electricity by harnessing the power of sea wave has been the most prominent research into renewable energy for over decades. Various researches have used various power take off mechanisms systems for converting wave power into electrical power such as the pelamis, oscillating water column, Archimedes wave swing etc. In this research, linear generator power take of method is used to convert the motion of wave at its interaction with the devices into electricity since this method offers a great power output at a minimum wave energy power than other methods. Feasibility studies to ascertain the exact location for mooring of the components were conducted using google search. The analysis of a hybrid quantitative and qualitative method is applied. In this aspect, statistical analysis of sea wave data and the consumption of electrical gadget of the faculty engineering of Regional Maritime University were analysed in order to design a suitable wave energy converter. Hydrodynamic analysis of wave energy converter was determined in order to establish the velocity of sea wave, for due to the incident wave, the energy from sea wave and the electrical power generated by the generator as a result of sea wave energy.
\end{abstract}

Keywords: Sea Wave, Power Take off, Hybrid, Qualitative, Quantitative, Electricity

\section{Introduction}

As fossil fuel is the main source of energy supply to the world's economy or the earth population (approximately 82\%) [1], the world faces future energy challenges. The increase in growth of human population and the demand for energy consumption rate will cause fossil fuel known to exist but not currently exploit to be depleted within decades. Due to high demands it will lead to an increase in fossil fuel prices, as it will become more and more difficult to exploit these natural resources in the deeper layer of the earth's crust [2]. However, the environmental impact of fossil fuel is also of concern. Power plants fired by fossil fuel emits or releases harmful chemicals such as $\mathrm{SO}_{2}, \mathrm{NO}_{2}$, and $\mathrm{CO}_{2}$, after combustion contributing to greenhouse effect leading to the depletion of the ozone layers affecting human and animal lives [3]. Due to the continuous fluctuation of the prices of oil and the environmental impact on the economy, a renewable energy becomes debatable issue. The generation of electricity by harnessing the power of sea wave has been the most prominent research into renewable energy for over decades. Renewable energy resources are currently too costly to compete with fossil fuels, but as time progresses it will become more economically viable to exploit renewable energy resources such as wave energy [4]. The first wave energy converters were design to have higher efficiency but the outcome was a complicated design that has failed to meet various necessities including cost and reliability [5]. However, simple modern WECs are design and tested to have higher efficiency that can stop $90 \%$ of the wave motion and convert all the wave motion to generate electricity given $81 \%$ efficiency [6]. Looking at the pumping action or kinetic power of the flowing current of the ocean waves near Regional Maritime University (RMU) which is located at Nungua, Accra Ghana, wave energy generation technology has been identified to be a promising technology to generate electricity for the faculty of Engineering, Regional Maritime University. This research is intended to carry a 
feasibility study for a possible Wave Energy Converter (WEC) at the shore of the University to generate electricity to run day to day activities of its faculty of Engineering.

\section{Classifications of Wave Energy Converter}

Converters are usually classified based on their positioning with respect to shore or the energy conversion mechanism adopted. Positioning classification include Shoreline devices, Near to shore devices and offshore devices. Under the shoreline devices, the devices are being placed on sea water in shallow, integrated in breakwater-like structures or coupled to a rocky cliff [7] With Near to shore devices, the devices are being deployed in approximately 10-20 metres of sea water depth, hundreds of meters measured from shore [8]. Under offshore devices, the floating devices are being places in deep water and are being moored to the floor of the sea and these devices represent the most promising class of wave energy converters. These devices may exploit huge wave potential for effective electricity.

Energy Conversion Mechanism

In addition to the previous classification for wave energy conversion is the power take off system which allows subclassification of the devices [9] Ideally, the power of wave is transferred to an auxiliary fluid usually air, water or oil which eventually induces a pressure difference. This fluid is an energy vector which triggers mechanical PTO system and eventually drives a variable speed power electronic generator [8]. The chain of electrical energy generated is as shown below:

$$
\text { Wave } \rightarrow \text { auxiliary fluid } \rightarrow \text { PTO system } \rightarrow \text { Electricity }
$$

Power take off system can be oscillating column of water, wave dragon system and underwater pneumatic system deep water and are being moored to the sea floor and these devices represent the promising class of wave energy converters [10]. These devices may exploit huge wave potential for effective electricity production [8].
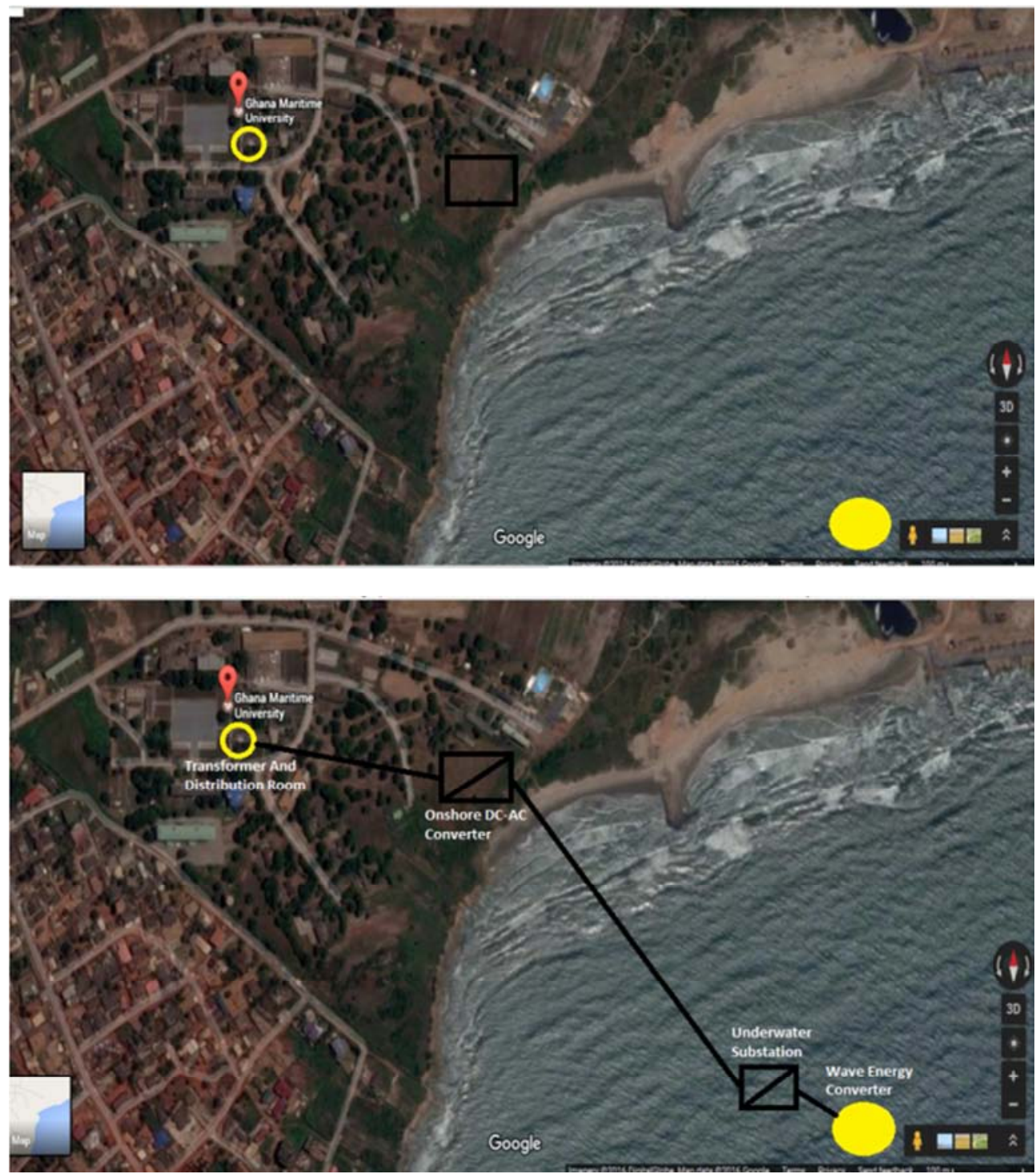

Figure 1. Area topology and the layout of components on site. 


\section{System Design}

\section{Feasibility Studies}

Feasibility studies were conducted to find a suitable place of offshore of Regional Maritime University for the installation of components selected for the design. In this case, google search approach is adopted and figure 1 show the area for deployment of the components.

\section{Components and Materials Selections}

The selection of components and materials for a design purpose is a formidable task as long as selecting the right one is concerned. The components selected must be able to perform their function effectively and efficiently within their expected time in service and must be easily manipulated. Various component parts are available for any design. However, factors of the design, characteristics and properties of these components must be considered to suit that particular design's function. The main properties to consider are physical, mechanical and chemical properties. The function to perform by the component, specification and also manufacturing cost are other factors to consider. Physical properties are the characteristics exhibited by the component when external forces are not acting upon them. They are mass, weight, density, etc. Chemical properties are those characteristics of the chemical composition of the component and their chemical reaction to the environment and other components, examples of the chemical properties are: corrosion resistance, rust resistance, etc. The mechanical properties are the characteristics exhibited when an external force is applied to them, such properties are hardness, toughness, fatigue resistance, malleability, tensile stress, tensile strength, creep resistance, compressive strength, hardness, etc.

Table 1. Components, Materials and their Properties.

\begin{tabular}{lll}
\hline Components & Material & Properties \\
\hline Buoy & Fiberglass, polyethylene, polyurethane & $\begin{array}{l}\text { Resistance to corrosion, light weight, low cost, good chemical } \\
\text { resistance. } \\
\text { Coil windings }\end{array}$ \\
$\begin{array}{l}\text { Permanent magnet } \\
\text { Seabed cables }\end{array}$ & Neodymium Iron Boron (Nd-Fe-B) & $\begin{array}{l}\text { High emf (depending on the size of the wave energy) } \\
\text { Underwater-converter substation. }\end{array}$ \\
$\begin{array}{ll}\text { Land cables } \\
\text { EPR, Hytrel, TPR, Megalon }\end{array}$ & $\begin{array}{l}\text { Converter valves, filters, capacitors, cables. } \\
\text { Copper, aluminum, steel }\end{array}$ & $\begin{array}{l}\text { Decreases voltage ripples, resistance to thermal stress } \\
\text { Cheaper, lighter, resist rusting }\end{array}$ \\
Mooring equipment & Fiber rope & $\begin{array}{l}\text { Adequate resistance to hydrolysis, chemicals, UV, fish bite, friction } \\
\text { and shear }\end{array}$ \\
\hline
\end{tabular}

\section{Generation System}

A suitable generator selected for this research must deliver power into the grid with constant frequency and rms voltage. Because the turbine rotates with a variable speed a synchronous machine is not suitable. Instead, a double fed wound rotor induction generator is used. The wound rotor is fed by the stator using a converter and with this arrangement the frequency and voltage is kept constant for a large range of turbine speed variation.

\section{Hydrodynamic Analysis}

Hydrodynamic control optimal strategy aims to find both elements (wave-buoy) in resonance in order to extract the maximum amount of wave energy. It is considered the simple case of a body oscillating in heave. The governing equation for the body oscillations is

$$
M * \ddot{Z}=f_{h}+f_{g}
$$

Where $M$ is the mass of the buoy-translator system, $\ddot{z}$ is the acceleration, $f_{h}$ is the vertical component of the force due to water pressure on the wetted surface of the body, $f_{g}$ is the vertical component of the force applied on the buoy by the PTO mechanism.

$$
\text { But } f_{h}=f_{d}+f_{r}+f_{h s}
$$

Where $f_{d}$ is the force produced by the incident waves on the assumed fixed body (excitation force), $f_{r}$ is the hydrodynamic force due to the body oscillation in otherwise calm water (radiation force), and $f_{h s}$ is the hydrostatic force give by;

$$
f_{h s}=\rho \cdot g \cdot S \cdot z
$$

Where $\rho$ is water density, $g$ is acceleration of gravity and $S$ is the buoy cross-sectional area defined by the undisturbed water free surface. In case of regular waves, it is convenient to decompose the radiation force as

$$
f_{r}=-m_{\text {add }} \cdot \ddot{z}-B \cdot \dot{z}
$$

Here $m_{a d d}$ is the added mass and $B$ is the radiationdamping coefficient. These parameters depend on the frequency of the waves and define the hydrodynamic characteristics of the buoy.

In case of regular waves of frequency $\omega_{w}$, the excitation force is a simple-harmonic function of time $t$;

$$
f_{d}=R_{e}\left(F_{d} \cdot e^{i \cdot \omega_{w} \cdot t}\right)
$$

Here $\omega_{w}$ is the regular wave frequency. The amplitude of this force can be obtained by; 


$$
F_{d}=\sqrt{\frac{2 \cdot g^{3} \cdot \rho \cdot B}{\omega^{3}}} \cdot A_{w}
$$

Where $A_{w}$ is the incident wave amplitude. If linear PTO system is assumed, it follows:

$$
f_{g}=-\gamma \cdot \dot{z}-k_{g} \cdot z
$$

Where $\gamma$ and $k_{g}$ are constants. The first term represents the damping effect associated with the energy extraction, while the second is a spring effect (which may exist or not). This term represents energy exchange between the PTO and the oscillating system, similar to the one done by a spring. If spring effect exists, there will be bidirectional energy exchange between thegenerator and the buoy. Thus, the electrical machine will operate as motor and generator alternatively. Taking into account the above considerations, the system is completely lineal and equation (1) may be written as:

$$
\begin{aligned}
&\left(M+m_{\text {add }}\right) \cdot \ddot{Z}+(B+\gamma) \cdot \dot{Z}+\left(\rho \cdot g \cdot S+k_{g}\right) \cdot Z= \\
& R_{e}\left(F_{d} \cdot e^{i \cdot \omega_{w} \cdot t}\right)
\end{aligned}
$$

Note the similarity between equation and the one regarding to RLC series circuit fed by sinusoidal voltage. The resonant frequency of the oscillating system is

$$
\begin{gathered}
\omega_{o}=\sqrt{\frac{k}{m_{T}}} \\
\omega_{o}=\sqrt{\frac{\rho \cdot g \cdot S+k_{g}}{M+m_{a d d}}}
\end{gathered}
$$

To extract the maximum wave energy amount, two conditions must fulfil:

a. The natural oscillation frequency of the oscillating system must match the wave frequency (resonance).

b. The damping force constant from the generator should be controlled equalling to the radiation-damping coefficient.

$$
\begin{gathered}
\omega_{O}=\omega_{w} \\
\gamma=B
\end{gathered}
$$

\subsection{Optimal Strategy to Extract Wave Energy}

The optimum conditions may be obtained by controlling the force that the generator applies to the oscillating system. Matching the constants $k_{g}$ and $\gamma$ in equation (7), the two conditions for optimization may be fulfilled. If the power converter allows bidirectional power flow, the resonant frequency of the oscillating device can be modified and will depend on the control strategy applied to the generator. Thus, to extract the maximum wave energy, the force exerted by the PTO must be calculated by the constants:

$$
\begin{gathered}
\gamma_{o p}=B+k_{g} \\
\omega_{o}^{2}=\frac{\rho \cdot g \cdot S+k_{g}}{m+m_{a d d}} \\
k_{g}=\omega_{o}^{2}\left(m+m_{a d d}\right)-\rho . g . S
\end{gathered}
$$

$$
k_{g_{-} o p}=\omega_{o}^{2}\left(M+m_{\text {add }}\right)-\rho \cdot g \cdot S
$$

In the system discussed in this thesis, the linear generator develops the force exerted by the PTO on the oscillating system. Its value will depend on the type of power converter and control strategy.

\subsection{Optimal Strategy Setting Null the PTO Stiffness Force}

In this case, the value of the constant $k_{g}$ is set null. There will be no energy transfer from the generator to the oscillating buoy system. Therefore, it would not be possible to change the resonant frequency of the oscillating device by acting on the generator control.

Systems where the value of the constant $\gamma$ may be controlled, the maximum wave energy extraction from equation (8) is achieved for:

$$
\begin{gathered}
\gamma_{s o}=B+k_{g} \\
\gamma_{s o}^{2}=B^{2}+k_{g}^{2} \\
k_{g}=\left\{\omega_{o}\left(M+m_{a d d}\right)-\frac{\rho \cdot g \cdot s}{\omega_{o}}\right\}^{2} \\
\gamma_{s o}^{2}=B^{2}+\left\{\omega_{o}\left(M+m_{a d d}\right)-\frac{\rho \cdot g \cdot s}{\omega_{o}}\right\}^{2} \\
\gamma_{s o}=\sqrt{B^{2}+\left\{\omega\left(M+m_{a d d}\right)-\frac{\rho \cdot g \cdot S}{\omega}\right\}^{2}}
\end{gathered}
$$

\subsection{Wave Energy and Wave-Energy Flux (Power)}

In a sea state, the average (mean) energy density per unit area of gravity waves on the water surface is proportional to the wave height squared, according to linear wave theory.

$$
E=\frac{1}{8} \rho \cdot g \cdot H^{2}
$$

Where $E$ is the mean wave energy density per unit horizontal area $\left(\mathrm{J} / \mathrm{m}^{2}\right)$. The potential energy density is equal to the kinetic energy, both contributing half to the wave energy density $E$.

As the waves propagate, their energy is transported. The energy transport velocity is the group velocities. As a result, the wave energy flux, through a vertical plane of unit width perpendicular to the wave propagation direction, is equal to;

$$
P=E . c_{-} g
$$

With $c_{g}$ the group velocities $(\mathrm{m} / \mathrm{s})$

$$
\begin{gathered}
c_{g}=\frac{g}{2 \omega} \\
P=\frac{1}{8} \rho \cdot g \cdot H^{2} \cdot \frac{g}{2 \omega}
\end{gathered}
$$

From $T=\frac{2 \pi}{\omega}, \omega=\frac{2 \pi}{T}$,

$$
\begin{gathered}
P=\frac{1}{8} \rho \cdot g \cdot H^{2} \cdot \frac{g}{2} \cdot \frac{T}{2 \pi} \\
P=\frac{\rho \cdot g^{2} \cdot H^{2} \cdot T}{32 \pi}
\end{gathered}
$$


Where:

$\mathrm{P}$ is the power of water wave present in depth (Kilo Watts), $\rho$ is seawater density $\left(1.025 \mathrm{~kg} / \mathrm{m}^{3}\right), \mathrm{g}$ is acceleration due to gravity $\left(9.81 \mathrm{~m} / \mathrm{s}^{2}\right), \mathrm{T}$ is wave period $(\mathrm{s}), \mathrm{H}$ is wave height (m).

\section{Modelling of Double -Fed Wound Rotor Induction Generator}

\subsection{Stator Equation of Doubly fed Induction Generator}

The Stator equation with speed of the stator in dq reference frame is given by:

$$
\begin{aligned}
& V_{d s t}=R_{s t} I_{d s t}-\omega \Psi_{d s t}+\frac{d \Psi_{d s t}}{d t} \\
& V_{q s t}=R_{s t} I_{q s t}-\omega \Psi_{q s t}+\frac{d \Psi_{q s t}}{d t}
\end{aligned}
$$

$V_{d s t}$ and $V_{q s t}$ are $\mathrm{d}$ and q axis stator voltages respectively. $I_{d s t}$ and $I_{q s t}$ are $\mathrm{d}$ and q axis stator current respectively.

\subsection{Rotor Equation of Doubly Fed Induction Stator}

$$
\begin{aligned}
& V_{d r t}=R_{r t} I_{d r t}-\left(\omega-\omega_{r}\right) \Psi_{d r t}+\frac{d \Psi_{d r t}}{d t} \\
& V_{q r t}=R_{r t} I_{q r t}-\left(\omega-\omega_{r}\right) \Psi_{q r t}+\frac{d \Psi_{q r t}}{d t}
\end{aligned}
$$

$V_{d r t}$ and $V_{q r t}$ are $\mathrm{d}$ and $\mathrm{q}$ axis rotor voltages respectively.

$I_{d r t}$ and $I_{q r t}$ are d and q axis rotor current respectively.

$R_{s t}$ and $R_{r t}$ are per phase stator and rotor resistance refer to stator

$\Psi_{d s t}$ and $\Psi_{q s t}$ are $\mathrm{d}$ and $\mathrm{q}$ axis stator flux linkage respectively

$\Psi_{d r t}$ and $\Psi_{\text {qrt }}$ are $\mathrm{d}$ and $\mathrm{q}$ axis rotor flux linkage respectively

$\omega$ and $\omega_{r}$ are rotational speed $\mathrm{dq}$ frame and rotor speed respectively.

The developed Torque

$$
\begin{gathered}
T_{d}=\frac{3 P}{4}\left(I_{q s t} \Psi_{d s t}-I_{d s t} \Psi_{q s t}\right) \\
\omega_{\mathrm{s}}=\frac{2 \cdot \pi \cdot \dot{\mathrm{z}}}{\lambda}
\end{gathered}
$$

Where $\lambda$ is the pole width of the generator

Thus, the active power at the generator input may be written as;

$$
\mathrm{P}_{\mathrm{pto}}=\frac{3}{2} \cdot \Psi_{\mathrm{dst}} \cdot \omega_{\mathrm{s}} \cdot \mathrm{I}_{\mathrm{qst}}
$$

The force applied on the buoy by the generator, may be calculated by the following expression;

$$
\begin{gathered}
\mathrm{f}_{\mathrm{pto}}=\frac{\mathrm{P}_{\mathrm{pto}}}{\dot{\mathrm{z}}} \\
\dot{\mathrm{z}}=\frac{\omega_{\mathrm{s}} \cdot \lambda}{2 \pi} \\
\mathrm{f}_{\mathrm{pto}}=\frac{3}{2} \cdot \Psi_{\mathrm{dst}} \cdot \omega_{\mathrm{s}} \cdot \mathrm{I}_{\mathrm{qst}} * \frac{2 \pi}{\omega_{s} \cdot \lambda}
\end{gathered}
$$

$$
\mathrm{f}_{\mathrm{pto}}=\frac{3 \cdot \Psi_{\mathrm{dst}} \cdot \mathrm{I}_{\mathrm{qst}} \cdot \pi}{\lambda}
$$

\subsection{Proposed Formulation}

The average power extracted by the PTO device over a wave period, is given by;

$$
\mathrm{P}_{\text {pto }}=\mathrm{r}_{\mathrm{pto}} \cdot \mathrm{U}
$$

Where $r_{p t o=} e m f=-N \cdot \frac{\Delta \emptyset}{\Delta t}$

Where $\emptyset=B A(\mathrm{~Wb})$

$$
B=\frac{\mu_{o} \cdot I}{2 \pi r}
$$

$\mathrm{B}=$ Magnetic field in tesla or weber $\left(1 \mathrm{~T}=1 \mathrm{Wbm}^{-2}\right), \mathrm{A}=$ Cross sectional area of the coil $\left(\mathrm{m}^{2}\right), \mathrm{N}=$ Number of coils, $\varnothing$ $=$ Magnetic flux, $\mathrm{r}=$ radial distance of the coil $(\mathrm{m}), \mu_{o}=$ permeability of free space $\left(4 \pi \times 10^{-7} T . m / A\right)$. The proposed formulation aims to calculate the power transferred to the electronic converter. Thus, generator copper losses are included in it. In this section, this power is formulated as a function of the PTO control parameters. The power transferred from the generator to the electronic converter can be expressed by;

$$
\mathrm{P}_{\mathrm{ec}}=\mathrm{P}_{\text {pto }}-\mathrm{P}_{\text {loss }}
$$

Where $P_{\text {loss }}$ are the linear generator copper losses, which is given by

$$
\mathrm{P}_{\text {loss }}=3 \mathrm{R}_{\mathrm{st}} \mathrm{I}^{2}
$$

Where I is the current supplied by the generator to the electronic converter and can be determine from:

$$
\mathrm{I}^{2}=\frac{\mathrm{I}_{\mathrm{qst}}^{2}}{2}
$$

\section{Sizing of the Plant}

\subsection{Hydrodynamic Analysis}

Using hydrodynamic analysis parameters data few of them is shown below;

$$
\begin{gathered}
M=2125 \mathrm{~kg}, M_{\text {add }}=15 \mathrm{~kg}, \ddot{Z}=0.063 \mathrm{~m} / \mathrm{s}^{2}, B=431 \mathrm{~N}_{\mathrm{s}} / \mathrm{m}, \\
\gamma=280 \mathrm{~N}_{\mathrm{s}} / \mathrm{m}, \dot{Z}=0.186 \mathrm{~m} / \mathrm{s}, \rho=1.025 \mathrm{~kg} / \mathrm{m}^{3}, \quad S=12.959 \mathrm{~m}^{2}
\end{gathered}
$$

The force acting on the device from equation (6) is given by

$$
f_{d}=R_{e}\left(F_{d} \cdot e^{i \cdot \omega_{w} \cdot t}\right)=807.454 \mathrm{~N}
$$

The optimal strategy to extract wave energy is:

$$
\begin{gathered}
k_{g_{-} o p}=\omega_{o}^{2}\left(M+m_{\text {add }}\right)-\rho \cdot g \cdot S \\
k_{g_{-} o p}=9578.660 \mathrm{~N}
\end{gathered}
$$

The Optimal strategy setting null the PTO stiffness force is: 


$$
\begin{gathered}
\gamma_{s o}=\sqrt{B^{2}+\left\{\omega\left(M+m_{a d d}\right)-\frac{\rho \cdot g \cdot S}{\omega}\right\}^{2}} \\
\gamma_{s o}=4517.639 \mathrm{~J}
\end{gathered}
$$

\subsection{Wave Power}

In order to determine the wave power, a rough estimate was considered at the sea Shore of Regional Maritime University. In this case, the height of the wave, the distance and the time taking for a wave to damped off to the shore is recorded for three different scenario. Using the transported wave power per unit of the wave front of period $\mathrm{T}$ and height $\mathrm{H}$ expression;

$$
P=\frac{\rho \cdot g^{2} \cdot H^{2} \cdot T}{32 \pi}
$$

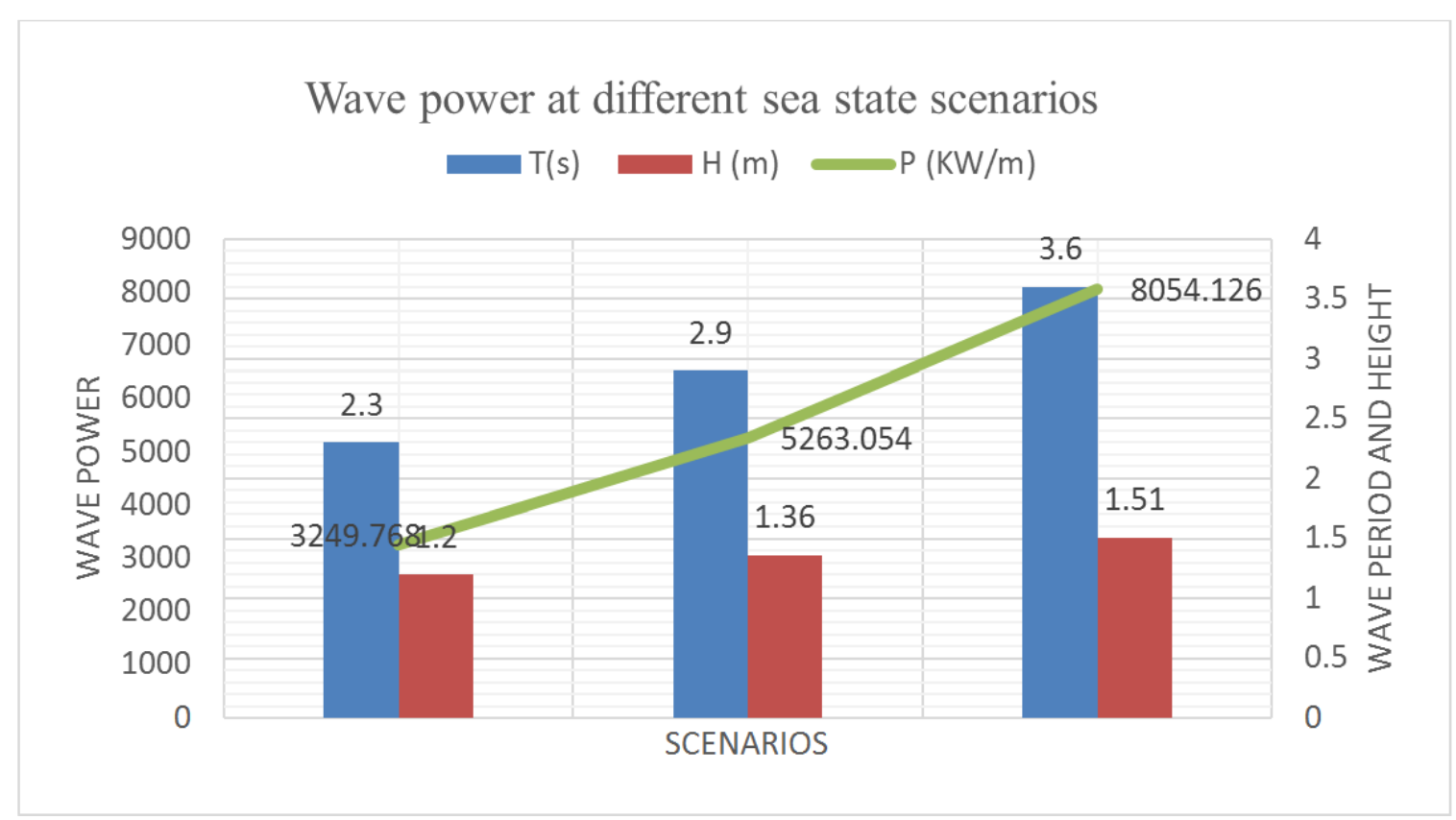

Figure 2. Wave Power at Different scenarios.

The wave power corresponding to each scenario is estimated as shown in the table above.

\subsection{Power Absorbed by the PTO System}

Using the power take off parameter data as shown below;

Table 2. Power take off data.

\begin{tabular}{ll}
\hline Parameters & Values \\
\hline Number of turns $(\mathrm{N})$ & 144 \\
Coil area (A) & $1.818 \mathrm{~m}^{2}$ \\
Magnetic field (B) & $0.290 \mathrm{Wbm}^{-2}$ \\
Time $(\mathrm{t})$ & $0.023 \mathrm{~s}$ \\
\hline
\end{tabular}

$$
\begin{gathered}
r_{p t o}=e m f=-N \cdot \frac{\Delta \emptyset}{\Delta t}, \text { where } \emptyset=B A \\
r_{p t o}=e m f=-3300,
\end{gathered}
$$

The maximum power extracted by the PTO device over a wave period at different scenario, is given by;

$$
\mathrm{P}_{\text {pto }}=\mathrm{r}_{\text {pto }} \cdot \mathrm{U}
$$

Where $U$ is the velocity of the wave. For the three scenario, the table below shows the power extracted by the PTO:
Table 3. Sammary of the three scenario.

\begin{tabular}{lll}
\hline Scenario & Nominal Speed (s) & Maximum power $(\mathbf{k W})$ \\
\hline A & 0.017 & 56.10 \\
B & 0.018 & 59.40 \\
C & 0.019 & 62.70 \\
\hline
\end{tabular}

The average power $\left(\mathrm{P}_{\text {pto }}\right)$ extracted by the PTO device over a wave period at different scenario is $59.4 \mathrm{Kw}$

Now using stator resistance and stator current, power loss is given by

$$
\mathrm{P}_{\text {loss }}=3 \mathrm{R}_{\mathrm{st}} \mathrm{I}^{2}=0.96 \mathrm{~W}
$$

Now the actual power from the converter of a doubled-fed wound rotor induction generator is $58.4 \mathrm{Kw}$.

The plant design is rated to produce a power of $58.4 \mathrm{~kW}$. The power produced will be feed to a seabed converter (underwater substation) through cables to the schools transformer. Seals will be used at different point to prevent the entering of water into the device, which will be change during maintenance when the need arises. The device is design in a way that allows for maintenance to be carried out on each component. 


\section{Design Drawing of Doubled-Fed Wound Rotor Induction Generator}

Component Dimensioning
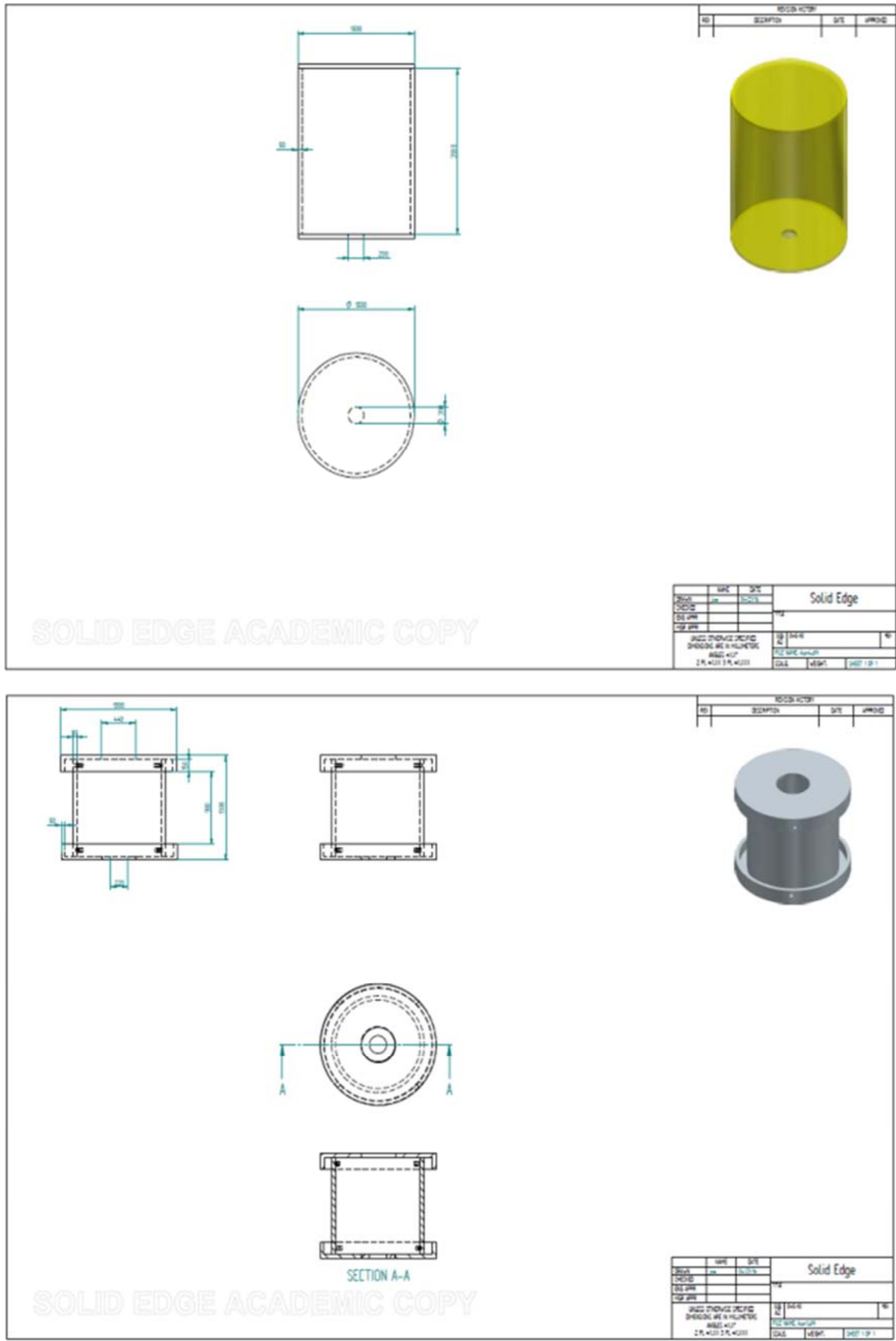

Figure 3. Cylidrical bouy and windings housing. 

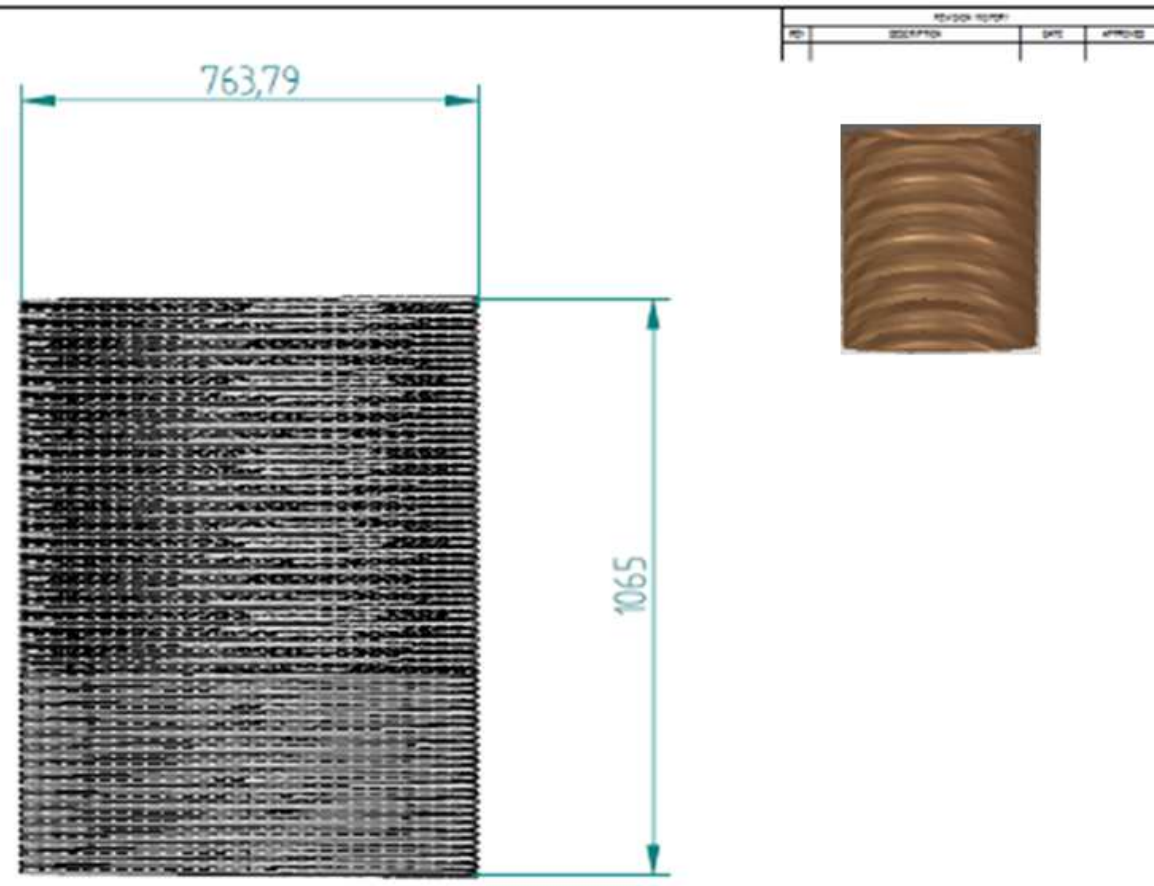

$$
\mathrm{N}=72
$$
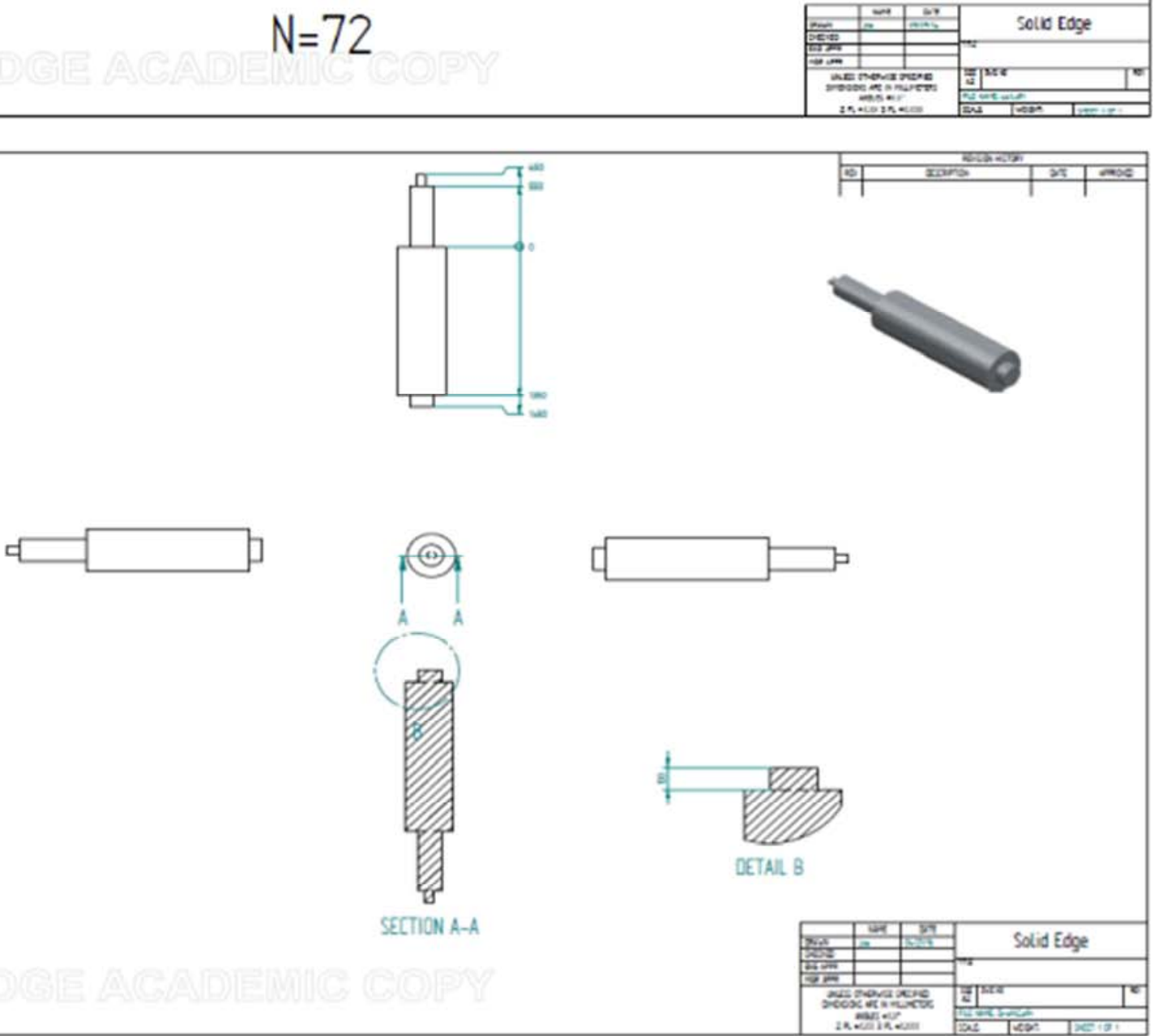

Figure 4. Coil windings and permanent magnetic shaft. 

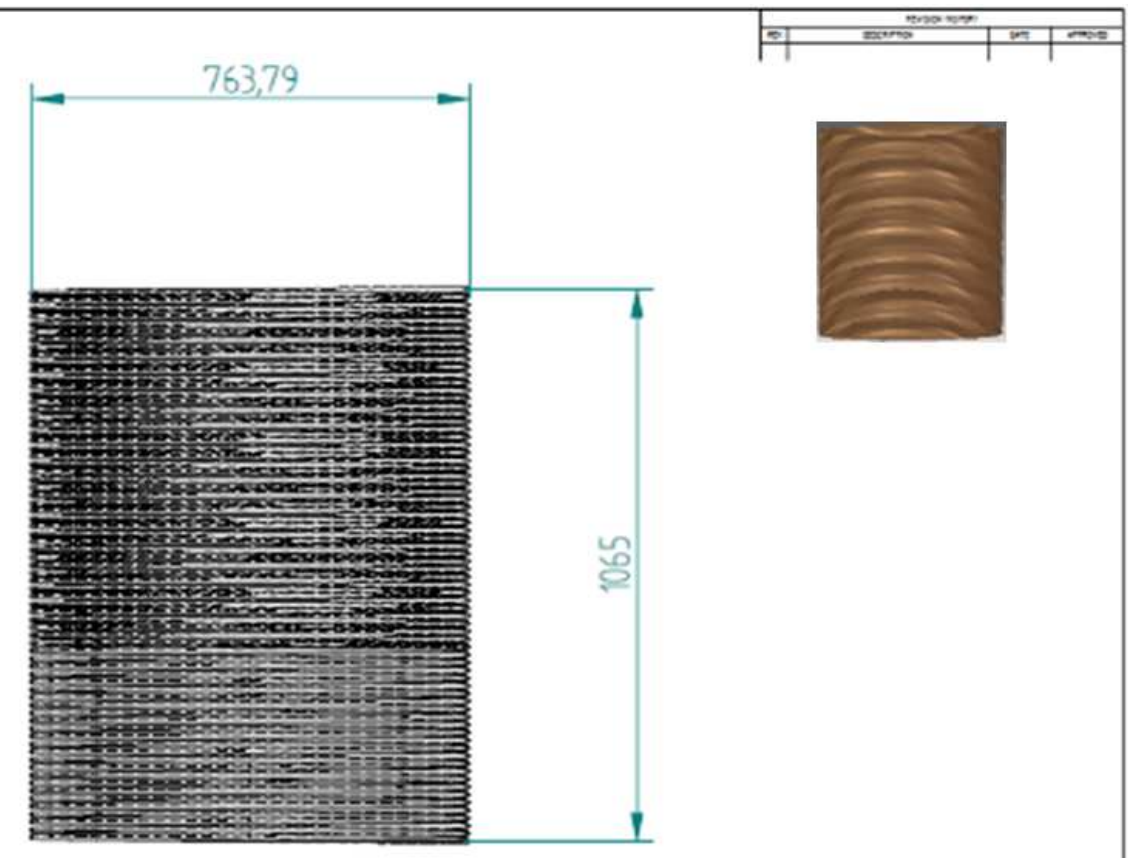

$N=144$
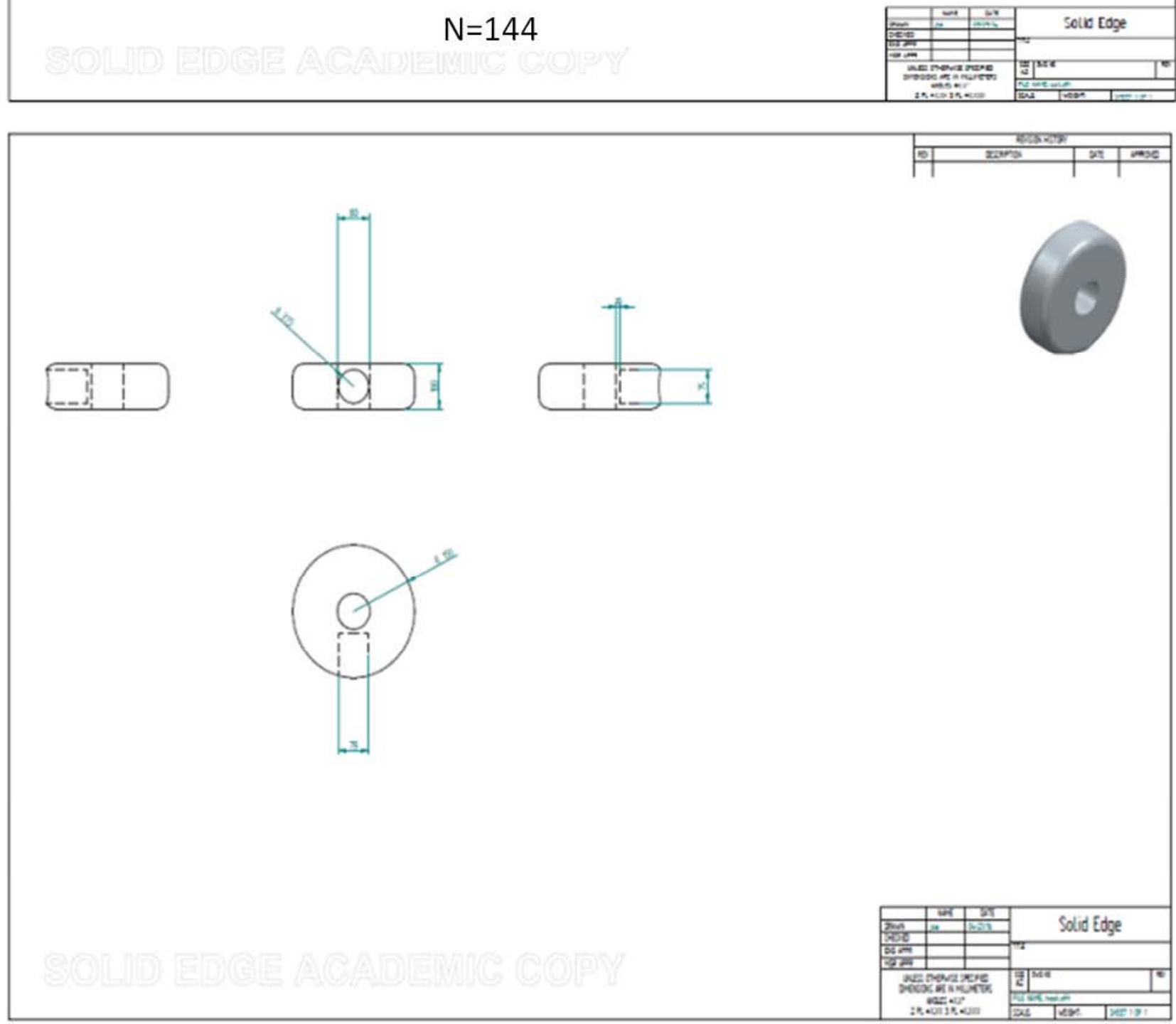

Figure 5. End stop and Generator. 

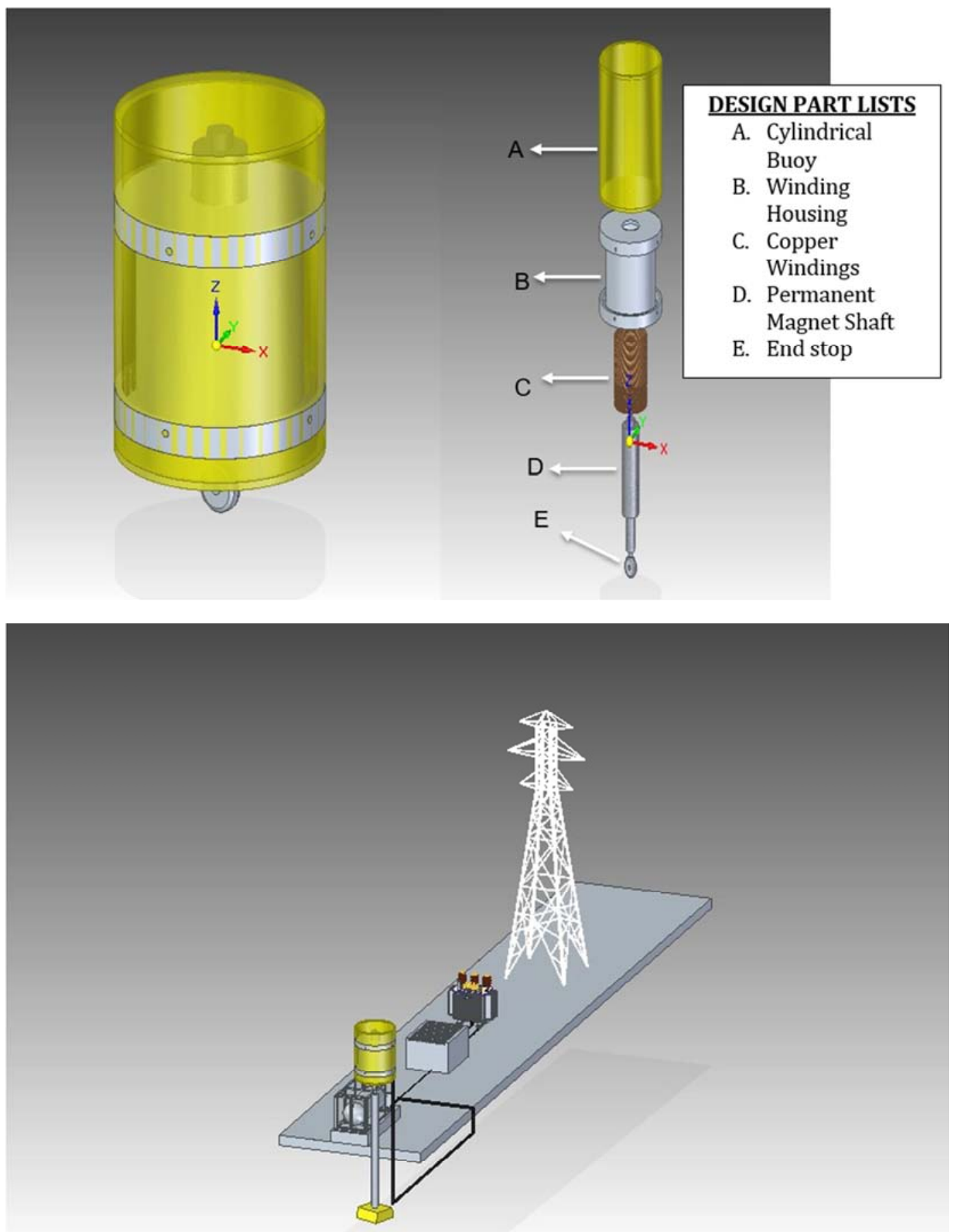

Figure 6. Exploded view of Generator and Plant Installation.

\section{Discussion of the Results}

In order to develop a more appropriate design, calculations have to be done to investigate the total amount of electrical power fed into the transformer and the maximum wave power extracted by the WEC device with different wave height and periods by simulating. Analysing the device in its environment determines the various forces acting on the device and their effects on the device. The force derived from the hydrodynamic analysis is $807.454 \mathrm{~N}$ which turns to be acting on the device possessed by the incident wave. Thus the device with its mooring equipment should be able to withstand this force considering the various materials used in the design to prevent fatigue failure. Optimum conditions were obtained in other to know the force exerted on heaving buoy by the generator. Thus to extract the maximum energy from the wave, the force exerted by the PTO device was found to be $9578.660 \mathrm{~N}$ and setting the stiffness force of the PTO to null, the maximum wave energy extracted by the device is $4517.639 \mathrm{~J}$. This works where unidirectional power converters are implemented. To achieve our desired output, sizing of the buoy and the generator were major factors. The 
shape, size and mass of the buoy and other components have great influences in the PTO mechanism. That is the more the buoy heaves, the faster and more power will be generated as a result of the induced emf in the windings. The power generated depends on the data presented on the generator sizing parameters. To know the power produced by the incident wave required for our PTO device, three different scenarios were considered and it has shown that, as the period and the wave height increase per each incoming wave, the wave power also increases. That is to say, the higher the wave period, the higher the wave power per meter crest. The resulting electrical power generated by the PTO from the wave power considering the relationship between the generated emf and different nominal speeds at different scenarios were calculated and where the final average power was found to be $59.4 \mathrm{~kW}$ after considering the power losses from the device. The plant designed was to produce $59.4 \mathrm{~kW}$ of power but considering the losses in the cables, a final output power of $58.4 \mathrm{~kW}$ was generated which is a positive result or respond.

\section{Conclusion}

In conclusion, the results obtained from field visited and feasibility study has been presented. Various forces acting on the device and their effects on the device as well as the converter design have also been presented. Optimum conditions were obtained in other to know the force exerted on our heaving buoy by the generator. Discussions on the WEC plant configuration and cost assumption for the system all highlighted. The generator rating which is $58.4 \mathrm{Kw}$ output is capable of supplying power to the whole of faculty of engineering of Regional Maritime University which has rough estimated load consumption of less than $40 \mathrm{~kW}$. Finally, the system design using Solid edge was also presented.

\section{References}

[1] Energypedia, "Ghana energy situation". [Online]. Available: http://www.energypedia.info. [Accessed October 2015].

[2] ESI AFRICA, "Ghana's Electricity Industry". [Online]. Available: http://www.esi-africa.com. [Accessed October 2015].

[3] F. E. Ankomah, "Ghana's electricity industry". [Online] Available: htttp://www.esi-africa.com. [Accessed 10 April 2016].

[4] Li Y., and Yu Y.-H. "A Synthesis of Numerical Methods for Modelling Wave Energy Converter-Point Absorbers," Renew. Sustain. Energy Rev., 16 (6), pp. 4352-4364, 2012.

[5] Drew, B., Plummer, A., and Sahinkaya. "A review of wave energy converter technology". Proceedings of the Institution of Mechanical Engineers, Journal of Power and Energy, vol. 223, no. 8, pp. 887-902, 2009.

[6] Evans, D. "Power from water waves". Annual Review of Fluid Mechanics, vol. 13, no. 1, pp. 157-187, 1981.

[7] Ridge, I. M. L., Banfield S. J., and Mackay J. Nylon fibre rope moorings for wave energy converters, Oceans, IEEE, Seattle, WA, United States, pp. 1-10, 2010.

[8] Leão Rodrigues. "Wave power conversion systems for electrical energy production" Department of Electrical Engineering, Faculty of Science and Technology, Nova University of Lisbon 2829-516 Caparica - PORTUGAL.

[9] A. Clement, P. McCullen, A. Falcao, A. Fiorentino, F. Gardner, K. Hammarlund, G. Lemonis, T. Lewis, K. Nielson, S. Petroncini, M.-T. Pontes, P. Schild, B.-O. Sjostrom and H. C. Sorensen, "Wave energy in Europe: current status and perspectives," Elsevier Science Ltd, 2002.

[10] Wave Dragon, "Wave Energy_a concentrated form of solar energy," [Online]. Available: http://www.wavedragon.net. [Accessed 2 April 2016]. 